\title{
Spatiotemporal Evolution of Population in Northeast China during 2012-2017: A Nighttime Light Approach
}

\author{
Haolin You, ${ }^{1}$ Cui Jin $\mathbb{D D}^{1},{ }^{1}$ and Wei Sun $\mathbb{D D}^{2}$ \\ ${ }^{1}$ Key Laboratory of Physical Geography and Geomatics, Liaoning Normal University, 116029 Dalian, China \\ ${ }^{2}$ Nanjing Institute of Geography and Limnology, Key Laboratory of Watershed Geographic Sciences, Chinese Academy of Sciences, \\ Nanjing 210008, China \\ Correspondence should be addressed to Cui Jin; cuijin@lnnu.edu.cn and Wei Sun; wsun@niglas.ac.cn
}

Received 5 April 2020; Accepted 7 May 2020; Published 28 May 2020

Guest Editor: Wen-Ze Yue

Copyright (C) 2020 Haolin You et al. This is an open access article distributed under the Creative Commons Attribution License, which permits unrestricted use, distribution, and reproduction in any medium, provided the original work is properly cited.

\begin{abstract}
Population is one of the key problematic factors that are restricting China's economic and social development. Previous studies have used nighttime light (NTL) imagery to calculate population density. This study analyzes the spatiotemporal evolution of the population in Northeast China based on linear regression analyses of NPP-VIIRS NTL imagery and statistical population data from 36 cities in Northeast China from 2012 to 2017. Based on a comparison of the estimation results in different years, we observed the following. (1) The population of Northeast China showed an overall decreasing trend from 2012-2017, with population changes of $+31,600,-960,800,-359,800,-188,000$, and $-1,127,600$ in the respective years. (2) With the overall population loss trend in Northeast China, the population increased in only three cities, namely, Shenyang, Dalian, and Panjin, with an average increase during the six-year period of 24,200, 6,500, and 2,000 people, respectively. (3) The four major urban agglomerations in Northeast China (the Harbin-Daqing-Qiqihar Industrial Corridor, Changjitu Pilot Zone, Liaoning Coastal Economic Belt, and Shenyang Economic Zone) have annual populations far exceeding 4 million people. A correct appreciation of the population dynamics is vital to resource management and comprehensive management efforts. Making full use of natural resources and regional advantages could effectively improve and potentially solve the urban population loss problem and would be of great innovative significance for supporting the realization of the Millennium Development Goals.
\end{abstract}

\section{Introduction}

Population is the precursor to social developments of humankind, and it has a significant impact on social development trends. With the rapid economic development of coastal areas, shifts in population have become even more apparent. After the establishment of the People's Republic of China, the three northeastern provinces of Liaoning, Jilin, and Heilongjiang, collectively known as Northeast China, became an important Chinese industrial base that has attracted many immigrants. In the past, the population of Northeast China maintained a rapid growth rate. However, according to data from the Sixth National Population Census of 2010, the population of Northeast China has decreased by $0.21 \%$ since the Fifth National Census in 2000. This significant loss of human resources has impeded the development and revitalization of the regional economy. Consequently, the topic of "population loss in Northeast China" has received widespread interest since the turn of the century $[1,2]$. At the same time, population flow can indicate the level of regional economic development. Therefore, a correct appreciation of population dynamics is vital to resource management and comprehensive management efforts. Different studies have shown that reasonable shifts in population are essential for regulating the population distribution and balancing regional economic development [3-8]. Achieving coordinated economic development should be a common goal of the global community [9]. Making full use of natural resources and regional advantages can effectively improve and solve the urban population loss problem and is of great innovative 
significance for supporting the realization of the Millennium Development Goals [10].

Until now, studies on population dynamics have focused primarily on aspects such as changes in population density [11-18], economic and social characteristics of population shifts [19-22], and relationships between population trends and regional economic development [23-27]. Demographic data used in this field are mainly derived from statistical surveys published by relevant national departments or online surveys. Traditional methods for collecting official statistics require significant labor resources, material resources, and time, especially for large-scale population statistics.

The development of remote sensing technology has provided an effective technique to collect population data. Nighttime satellite imagery can detect lights of different intensities, such as those generated by cities, small-scale residential areas, and traffic, thus providing an effective data source for monitoring human activity [28-30]. Additionally, the brightness of nighttime light (NTL) imagery can reflect the intensity of human activity and can be used as a new tool for large-scale urban research. Compared with the firstgeneration Defense Meteorological Satellite Program's Operational Linescan System (DMSP-OLS) NTL remote sensing data, the second-generation Suomi National PolarOrbiting Partnership Visible Infrared Imaging Radiometer Suite (NPP-VIIRS) data (first released in 2012) have higher spatial, temporal, and radiometric resolutions [31-33], which renders it more suitable for investigations of economic and social activities.

The NPP-VIIRS NTL satellite imagery has been widely used in studies involving urban-area extraction [34, 35], gross domestic product (GDP) estimation [24], powerconsumption estimation [36], floating population analysis [14], and economic activity analysis [37, 38]. Previous studies have used DMSP-OLS NTL data to estimate the population. For example, Croft [39] observed that NTL remote sensing data can closely reflect human activity and first proposed that DMSP-OLS images can be used to extract urban built-up areas. Sutton et al. [40] reported that the NTL intensity and population distribution of the continental United States have a good correlation, with a linear regression coefficient of 0.63 , thus providing an empirical basis for the examination of population density using NTL imagery. Based on the population regionalization concept, Kejing et al. [41] used DMSP-OLS NTL data to establish a multiscale spatialization model of demographic data from 2010 and applied it to estimations of the population size. However, oversaturation is a commonly occurring problem when using DMSP-OLS NTL imagery due to its limited digital number range of 0-63. In addition, as these studies used an annual temporal scale, they overlooked changes in population shifts during the Spring Festival and other holidays.

The purpose of this study was to analyze the population dynamics in Northeast China by using remote sensing and geographic information system (GIS) technology. We used monthly composites of high-quality NPP-VIIRS NTL images in combination with census data to obtain and analyze the population trends of 36 cities in Northeast China, and these results can provide a reference for initiatives aimed at the return of talents and stable economic development in Northeast China.

\section{Materials and Methods}

2.1. Study Area. Northeast China $\left(38^{\circ} \mathrm{N}-56^{\circ} \mathrm{N}, 120^{\circ} \mathrm{E}-135^{\circ} \mathrm{E}\right)$ encompasses the provinces of Liaoning, Jilin, and Heilongiiang, with a total land area of $787,300 \mathrm{~km}^{2}$, and it accounts for $8.20 \%$ of China's total area. Among these areas, Liaoning province includes 14 prefecture-level cities, Jilin province includes eight prefecture-level cities and Yanbian, an autonomous prefecture, and Heilongjiang province includes 12 prefecture-level cities and Daxing'anling, a prefecture-level region (as shown in Figure 1).

2.2. Data Sources. The main data used in the study included demographic data, imagery data, and administrative division data (as shown in Table 1).

2.3. Image Denoising. The raw NTL data contained negative pixels, which were regarded as background noise generated during data synthesis. In certain studies, these negative values have been replaced with 0 values [38]. In this study, the negative pixel values in the NPP-VIIRS NTL imagery were replaced with a 0 value to ensure data integrity for subsequent calculations.

To remove isolated pixels with a high brightness in the NPP-VIIRS data, all pixel values were arranged in ascending order. A threshold of $99 \%$ was selected as the digital number maximum (DNM), such that that any pixels with values exceeding the threshold were assigned the DNM [39].

2.4. Selection of Appropriate Months. The selection of appropriate months can have a significant effect on the study of population dynamics [14]. In this study, one or several months with relatively stable light conditions were selected in each year to eliminate the impact that increased population movements during public holidays, when large numbers of students and migrant workers travel across China, have on the results of this study. The raw images used in this study did not include data for the months of May, June, and July because of the lack of original images. After extracting the digital number (DN) of the NTL pixels, we found that certain data were missing in the April and August images. Consequently, the months of April, May, June, July, and August were excluded from this study.

After image preprocessing, the selected images were processed by using zonal statistics as table method to obtain the brightness distribution of each image. A comparative analysis of the DN pixel values of the monthly NTL composites from 2012 to 2017 was performed to select the months with stable light conditions, which were used to represent the NTL conditions of an entire year.

As the shift in population increases significantly during holiday periods, the use of NTL data from these months to 


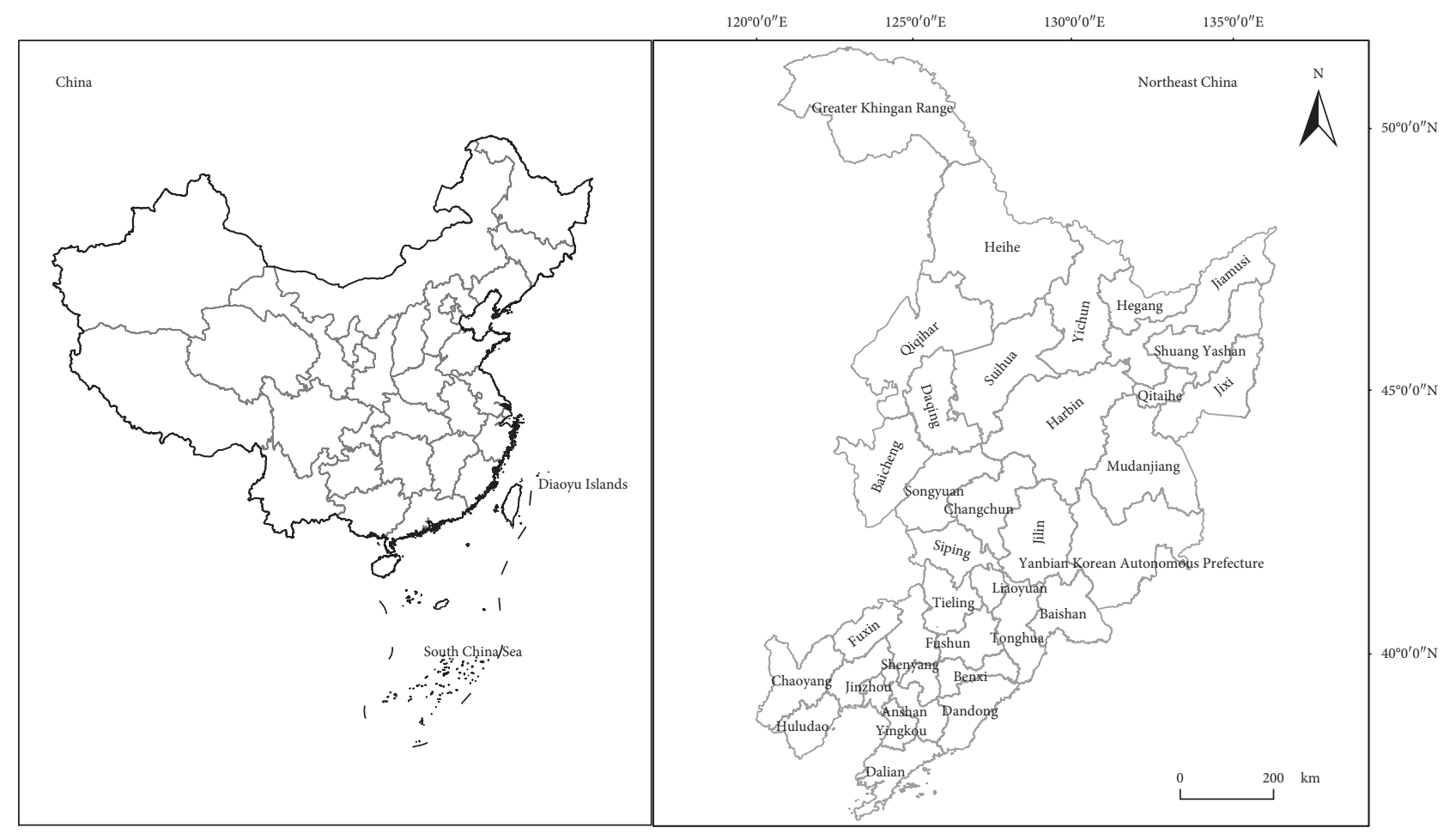

Figure 1: Study area map.

TABle 1: Data sources and descriptions.

\begin{tabular}{|c|c|c|c|c|c|}
\hline Year & Data & $\begin{array}{l}\text { Spatial } \\
\text { resolution }(\mathrm{m})\end{array}$ & Source & Details & Purpose \\
\hline $\begin{array}{l}2012-2017 \\
6 \text { years }\end{array}$ & $\begin{array}{l}\text { NPP-VIIRS } \\
\text { nighttime light } \\
\text { imagery }\end{array}$ & \multirow{3}{*}{500} & $\begin{array}{l}\text { NASA official website (https://www.ngdc.noaa. } \\
\text { gov/eog/viirs/download_dnb_composites. } \\
\text { html) }\end{array}$ & $\begin{array}{l}\text { Total of } 51 \\
\text { images, grid } \\
\text { data }\end{array}$ & $\begin{array}{l}\text { Population } \\
\text { inversion }\end{array}$ \\
\hline \multirow{2}{*}{$\begin{array}{l}2012-2017, \\
6 \text { years }\end{array}$} & Demographic data & & National Census data (http://www.stats.gov.cn/) & $\begin{array}{l}\text { Average value } \\
\text { in } 2012-2017\end{array}$ & $\begin{array}{l}\text { Calculation } \\
\text { verification }\end{array}$ \\
\hline & $\begin{array}{l}\text { Administrative } \\
\text { division data }\end{array}$ & & $\begin{array}{l}\text { National Catalogue Service for Geographic } \\
\text { Information (http://www.webmap.cn) }\end{array}$ & Vector data & $\begin{array}{l}\text { Map of study } \\
\text { area }\end{array}$ \\
\hline
\end{tabular}

calculate the population size would result in larger errors. Consequently, we must select appropriate monthly images to calculate the average annual nighttime image. Here, the NPP-VIIRS NTL images of seven months were selected for DN value extraction to analyze the urban lighting conditions of 36 cities in Northeast China. The extracted NTL values in each month were comparatively analyzed to select the months with the most stable light conditions for image synthesis, with the objective of minimizing the impact that unusually high population movements have on urban lighting conditions.

2.5. Population Spatialization. Based on the findings of previous studies with respect to the relationship between the population size and NTL data [42], we performed a polynomial correlation analysis of the extracted NTL DN values and statistical data. The results were used to calculate the population of 36 cities in Northeast China. The estimated populations were then used to analyze the population dynamics of Northeast China from 2012 to 2017.
(1) Spatial regression population model

Previous studies have shown that NPP-VIIRS NTL data can be used for population spatial analyses [42, 43]. The following function represents the relationship between the population size and radiance of NPP-VIIRS DNB (day/night band) NTL data:

$$
\overline{\mathrm{POP}}=a x^{3}+b x^{2}+c x+d,
$$

where $\overline{\mathrm{POP}}$ is the regression result for the urban resident population, $x$ is the NPP-VIIRS DNB radiance, and $a, b, c$, and $d$ are the cubic polynomial coefficients.

(2) Precision testing and result adjustment

The relative error between the regression results and statistical data can be obtained with the following expression:

$$
\gamma=\frac{|\overline{\mathrm{POP}}-\mathrm{POP}|}{\mathrm{POP}} * 100 \% \text {, }
$$


where $\gamma$ is the relative error, $\overline{\mathrm{POP}}$ is the regression result for permanent urban residents, and POP is the size of the permanent urban population.

As the estimation results had high relative errors, further data processing was required [44]. The NPP-VIIRS data can be corrected by using a power function by establishing adjustment parameters for each city to render the estimated annual population of each city consistent with the actual number of permanent residents obtained via statistical methods. This is expressed in the following equation:

$$
\begin{gathered}
c_{n}=\frac{\mathrm{POP}_{n}}{\mathrm{POP}_{\text {total }},} \\
f_{n}=c_{n} * \mathrm{DNB}_{n},
\end{gathered}
$$

where $c$ is the adjustment parameter, $n$ is the year, $\mathrm{POP}_{\text {total }}$ is the total permanent urban population, $f_{n}$ is the adjusted brightness value, and DNB is the brightness value before correction.

\section{Results}

3.1. Selection of Appropriate Months. Seasonal changes have a significant impact on the population shift and light intensity [14]. We compared the DN values of the monthly NTL composites from 2012-2017 (as shown in Figure 2).

Based on Figure 2, the DN values of the monthly composite images showed significant interannual fluctuations. Therefore, months with smaller variations were selected for the annual composites to avoid the impact that large population shifts, such as those during holiday periods, have on the annual composite images. The DN values of the March and September composites were relatively stable, such that the mean composites of these two months were used to construct the annual NTL composite image for the investigation of the changes in the population of 36 cities in Northeast China.

3.2. Population Spatialization. Based on the results of previous studies that computed population sizes by using NTL data [45], we performed a linear correlation analysis of NTL DN values and statistical population data to estimate the population of 36 cities in Northeast China. To better understand the spatial and temporal distribution trends of urban populations in Northeast China, the spatial distribution of the population was analyzed based on the estimated population size from 2012-2017.

As shown in Table 2, we observed that Harbin, Changchun, and Shenyang, which are the provincial capitals of Heilongjiang, Jilin, and Liaoning, respectively, consistently ranked as the top three in terms of population size. The population of each province decreased radially outward from their respective capitals, which are the population centers. From a spatial development perspective, the provincial capital cities of Northeast China were well developed and had relatively large populations. As an important industrial base of Northeast China, Harbin has experienced rapid economic and social development; its population was

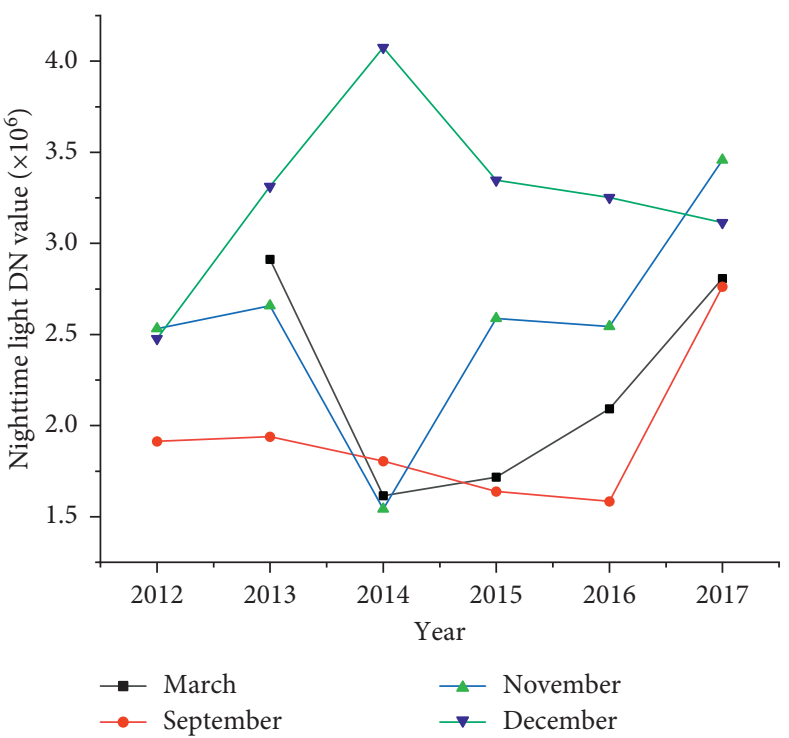

Figure 2: Comparison of moon lights from 2012-2017.

also the largest. Despite its declining population, Dalian consistently ranked fourth, whereas Daxing'anling and Qitaihe, which are characterized by their high latitude and sparse populations, ranked last among the 36 cities. The overall population of all three provinces decreased from 2012 to 2017. Although the magnitude of this decline varied in each province, the order remained essentially the same each year.

The overall spatial distribution of the population density in Northeast China remained essentially unchanged, i.e., the overall population density in the central and southern regions was consistently higher than that of the surrounding regions. From 2012 to 2017, the overall distribution of the population in Northeast China had a T-shaped multicenter spatial agglomeration pattern with the provincial capitals at the center. The highest population concentrations occurred along the main arterial routes. Based on the spatial analysis of the estimated populations in Table 2, the population distribution of Northeast China forms a "core-periphery" model, with the highest population centered in the provincial capitals and the city of Dalian, followed by a gradually decreasing outward pattern [46].

The Fifth National Population Census found that the labor force participation rate for age groups 15-29, 30-49, and 50-65 in Northeast China was 32.82, 50.10, and $17.08 \%$, respectively. At the time of the Sixth Census, the labor participation rate for the same three age groups was $27.42,46.50$, and $26.08 \%$, respectively $[47,48]$. The census data showed that the proportion of the young and middleage labor force in this region is decreasing while the proportion of older workers is increasing, thus indicating that the loss of a young labor force and population aging pose a serious problem in Northeast China. From a longterm perspective, the continuous outflow of young and prime-age skilled and unskilled labor has significantly reduced the innovative capacity of this region, which has led to stagnant regional production and inhibited economic development. 
TABLe 2: Estimated population in Northeast China from 2012-2017.

\begin{tabular}{|c|c|c|c|c|c|c|}
\hline City & 2012 & 2013 & 2014 & 2015 & 2016 & 2017 \\
\hline Shenyang & 724.68 & 730.01 & 732.08 & 730.35 & 731.19 & 736.78 \\
\hline Dalian & 592.25 & 592.24 & 592.80 & 593.21 & 596.25 & 595.50 \\
\hline Anshan & 349.92 & 348.79 & 349.51 & 346.17 & 345.64 & 344.10 \\
\hline Fushun & 220.04 & 218.03 & 215.20 & 214.54 & 215.28 & 214.52 \\
\hline Benxi & 151.03 & 152.56 & 151.84 & 151.94 & 150.07 & 151.03 \\
\hline Dandong & 240.23 & 239.69 & 239.64 & 238.12 & 237.80 & 235.15 \\
\hline Jinzhou & 306.94 & 306.18 & 303.22 & 304.88 & 304.23 & 296.82 \\
\hline Yingkou & 234.99 & 233.10 & 232.55 & 233.34 & 232.58 & 232.54 \\
\hline Fuxin & 191.34 & 191.22 & 189.99 & 190.57 & 189.25 & 186.27 \\
\hline Liaoyang & 180.00 & 180.13 & 179.26 & 179.64 & 177.65 & 177.40 \\
\hline Panjin & 129.29 & 129.78 & 129.42 & 130.17 & 130.19 & 130.26 \\
\hline Tieling & 301.82 & 301.97 & 301.10 & 300.94 & 299.69 & 293.52 \\
\hline Chaoyang & 340.55 & 339.31 & 340.50 & 340.54 & 340.94 & 336.30 \\
\hline Huludao & 280.02 & 280.03 & 280.57 & 280.19 & 280.71 & 277.09 \\
\hline Changchun & 755.02 & 752.41 & 754.39 & 754.93 & 754.57 & 748.99 \\
\hline Jilin & 428.96 & 422.67 & 422.46 & 425.11 & 418.48 & 413.73 \\
\hline Siping & 332.43 & 332.42 & 327.73 & 326.32 & 324.65 & 320.44 \\
\hline Liaoyuan & 120.95 & 121.61 & 121.59 & 120.05 & 119.97 & 117.29 \\
\hline Tonghua & 223.75 & 223.04 & 221.28 & 221.99 & 219.97 & 217.07 \\
\hline Baishan & 128.44 & 126.70 & 125.01 & 123.86 & 124.05 & 119.63 \\
\hline Songyuan & 289.53 & 284.38 & 278.21 & 278.73 & 279.39 & 275.44 \\
\hline Baicheng & 199.72 & 200.08 & 197.87 & 196.20 & 195.40 & 190.97 \\
\hline Yanbian (Korean Autonomous Prefecture) & 213.13 & 214.24 & 213.68 & 214.58 & 213.52 & 210.31 \\
\hline Harbin & 980.48 & 995.10 & 984.80 & 958.70 & 984.47 & 967.11 \\
\hline Qiqihar & 561.11 & 557.14 & 550.39 & 550.77 & 546.42 & 534.97 \\
\hline Jixi & 183.50 & 186.99 & 182.54 & 182.47 & 183.51 & 175.51 \\
\hline Hegang & 106.83 & 108.21 & 104.87 & 107.51 & 103.33 & 104.19 \\
\hline Shuangyashan & 149.42 & 149.31 & 150.16 & 145.61 & 144.86 & 142.79 \\
\hline Daqing & 280.20 & 282.63 & 279.72 & 277.32 & 277.42 & 278.49 \\
\hline Yichun & 125.15 & 123.70 & 121.78 & 122.92 & 117.63 & 117.99 \\
\hline Jiamusi & 234.33 & 242.10 & 231.27 & 233.73 & 231.00 & 225.61 \\
\hline Qitaihe & 92.47 & 91.89 & 88.28 & 81.40 & 79.63 & 80.71 \\
\hline Mudanjiang & 256.52 & 264.34 & 255.03 & 255.11 & 253.69 & 246.23 \\
\hline Heihe & 166.54 & 170.37 & 169.50 & 167.63 & 168.90 & 162.84 \\
\hline Suihua & 556.41 & 567.06 & 546.07 & 551.92 & 542.85 & 544.36 \\
\hline Daxing'anling & 50.93 & 51.09 & 50.14 & 46.99 & 44.50 & 44.94 \\
\hline
\end{tabular}

As shown in Table 3, the average error between the estimated and statistical populations was controlled to within $1 \%$ as much as possible. For Hegang, Heihe, and Suihua, however, the average errors exceeded the control value at $1.54,1.63$, and $1.80 \%$, respectively. The population estimation error based on the NTL images was relatively high for these cities because of their high latitude and sparse populations.

3.3. Spatiotemporal Evolution of the Urban Population. The total population of Northeast China from 2012-2017 (Figure 3) was estimated at 106.79, 107.11, 106.14, 105.78, 105.60, and 104.47 million, respectively. From 2012-2017, the overall trend in Northeast China showed a decline in the population. During this period, the overall population changed by $+316,000,-960,800,-359,800,-188,000$, and $-1,127,600$ people annually.

Compared with 2012, the population increased by 316,000 in 2013 , followed by a decline in the population every year thereafter. In 2017, the decline in the population was particularly large, during which it decreased by $1,127,600$ compared with 2016; this indicates that the population outflow problem is particularly serious. These declining populations will continue to affect the economic development of Northeast China.

Figure 4 shows that the estimated population of Northeast China had an overall trend of Liaoning > Heilongjiang $>$ Jilin. From 2012-2017, the population of Liaoning was 42.43, 42.43, 42.38, 42.35, 42.31, and 42.07 million, respectively, and it decreased by 400, 53,800, 30,800, 31,500 , and 241,700 people, respectively. In the same period, the population of Jilin was 26.92, 26.78, 26.62, 26.62, 26.50, and 26.14 million, respectively, with a decline of 143,900 , $153,300,4,500,117,700$, and 361,300 people in the respective years. From 2012-2017, the estimated population of Heilongjiang was $37.44,37.90,37.15,36.82,36.78$, and 36.26 million, respectively, and there was first an increasing trend by 460,300 and then a decreasing trend by $753,800,324,600$, 38,900 , and 524,600 in the respective years.

Based on the estimation data, the only population increase of 430,600 occurred in Heilongjiang province in 2013, 
TABLE 3: Relative error between the estimated population and statistical population in Northeast China from $2012-2017$.

\begin{tabular}{|c|c|c|c|c|c|c|c|}
\hline City & 2012 & 2013 & 2014 & 2015 & 2016 & 2017 & Average error (\%) \\
\hline Shenyang & $-0.02 \%$ & $0.40 \%$ & $0.18 \%$ & $-0.01 \%$ & $-0.37 \%$ & $0.04 \%$ & 0.17 \\
\hline Dalian & $0.33 \%$ & $0.14 \%$ & $-0.25 \%$ & $-0.07 \%$ & $0.11 \%$ & $0.10 \%$ & 0.17 \\
\hline Anshan & $-0.11 \%$ & $-0.29 \%$ & $0.38 \%$ & $0.05 \%$ & $-0.02 \%$ & $0.03 \%$ & 0.14 \\
\hline Fushun & $0.34 \%$ & $0.02 \%$ & $-1.01 \%$ & $-0.58 \%$ & $0.23 \%$ & $1.81 \%$ & 0.66 \\
\hline Benxi & $-1.41 \%$ & $0.17 \%$ & $-0.10 \%$ & $0.49 \%$ & $0.05 \%$ & $2.32 \%$ & 0.76 \\
\hline Dandong & $-0.11 \%$ & $0.04 \%$ & $0.06 \%$ & $0.01 \%$ & $-0.04 \%$ & $-0.02 \%$ & 0.05 \\
\hline Jinzhou & $-0.28 \%$ & $0.09 \%$ & $-0.68 \%$ & $0.76 \%$ & $0.67 \%$ & $0.17 \%$ & 0.44 \\
\hline Yingkou & $-0.05 \%$ & $0.26 \%$ & $-0.32 \%$ & $0.32 \%$ & $-0.10 \%$ & $0.32 \%$ & 0.23 \\
\hline Fuxin & $-0.14 \%$ & $0.06 \%$ & $-0.53 \%$ & $0.57 \%$ & $0.18 \%$ & $0.04 \%$ & 0.25 \\
\hline Liaoyang & $-0.17 \%$ & $0.07 \%$ & $-0.35 \%$ & $0.36 \%$ & $-0.53 \%$ & $0.51 \%$ & 0.33 \\
\hline Panjin & $0.38 \%$ & $0.61 \%$ & $0.17 \%$ & $0.52 \%$ & $0.07 \%$ & $0.51 \%$ & 0.37 \\
\hline Tieling & $-0.13 \%$ & $0.02 \%$ & $-0.30 \%$ & $0.18 \%$ & $-0.07 \%$ & $-0.06 \%$ & 0.13 \\
\hline Chaoyang & $-0.01 \%$ & $-0.06 \%$ & $-0.03 \%$ & $-0.11 \%$ & $-0.05 \%$ & $-0.06 \%$ & 0.05 \\
\hline Huludao & $0.01 \%$ & $0.05 \%$ & $-0.05 \%$ & $0.03 \%$ & $0.07 \%$ & $0.03 \%$ & 0.04 \\
\hline Changchun & $-0.25 \%$ & $-0.03 \%$ & $-0.02 \%$ & $0.15 \%$ & $0.15 \%$ & $0.01 \%$ & 0.10 \\
\hline Jilin & $-0.42 \%$ & $-1.50 \%$ & $-1.21 \%$ & $-0.27 \%$ & $-0.94 \%$ & $-0.39 \%$ & 0.79 \\
\hline Siping & $-1.16 \%$ & $1.22 \%$ & $-0.11 \%$ & $-0.03 \%$ & $0.05 \%$ & $0.01 \%$ & 0.43 \\
\hline Liaoyuan & $-0.86 \%$ & $-0.25 \%$ & $-0.17 \%$ & $-0.62 \%$ & $0.14 \%$ & $-0.56 \%$ & 0.43 \\
\hline Tonghua & $-0.38 \%$ & $0.33 \%$ & $-0.41 \%$ & $0.40 \%$ & $0.05 \%$ & $-0.04 \%$ & 0.27 \\
\hline Baishan & $0.45 \%$ & $-0.34 \%$ & $-0.99 \%$ & $-1.20 \%$ & $2.02 \%$ & $0.09 \%$ & 0.85 \\
\hline Songyuan & $-0.09 \%$ & $0.50 \%$ & $-0.09 \%$ & $0.24 \%$ & $0.37 \%$ & $0.01 \%$ & 0.22 \\
\hline Baicheng & $-0.15 \%$ & $0.49 \%$ & $0.06 \%$ & $-0.24 \%$ & $1.00 \%$ & $0.01 \%$ & 0.33 \\
\hline Yanbian (Korean Autonomous Prefecture) & $-0.04 \%$ & $-0.34 \%$ & $-0.42 \%$ & $0.47 \%$ & $0.70 \%$ & $0.08 \%$ & 0.34 \\
\hline Harbin & $-1.31 \%$ & $-0.01 \%$ & $-0.25 \%$ & $-0.28 \%$ & $2.33 \%$ & $1.27 \%$ & 0.91 \\
\hline Qiqihar & $0.37 \%$ & $0.03 \%$ & $-0.51 \%$ & $0.25 \%$ & $0.36 \%$ & $0.24 \%$ & 0.29 \\
\hline Jixi & $-1.30 \%$ & $0.21 \%$ & $-0.56 \%$ & $0.72 \%$ & $1.53 \%$ & $0.26 \%$ & 0.76 \\
\hline Hegang & $-1.54 \%$ & $0.38 \%$ & $-2.01 \%$ & $1.80 \%$ & $-0.29 \%$ & $3.22 \%$ & 1.54 \\
\hline Shuangyashan & $-0.66 \%$ & $-0.33 \%$ & $0.78 \%$ & $-1.24 \%$ & $0.20 \%$ & $0.35 \%$ & 0.59 \\
\hline Daqing & $-0.54 \%$ & $0.01 \%$ & $0.62 \%$ & $-0.06 \%$ & $-0.14 \%$ & $0.25 \%$ & 0.27 \\
\hline Yichun & $0.83 \%$ & $0.41 \%$ & $-0.93 \%$ & $1.43 \%$ & $0.04 \%$ & $1.78 \%$ & 0.90 \\
\hline Jiamusi & $-2.12 \%$ & $0.00 \%$ & $-0.68 \%$ & $1.98 \%$ & $0.83 \%$ & $-0.27 \%$ & 0.98 \\
\hline Qitaihe & $0.11 \%$ & $-0.12 \%$ & $0.06 \%$ & $-2.06 \%$ & $-0.63 \%$ & $2.68 \%$ & 0.94 \\
\hline Mudanjiang & $-1.17 \%$ & $-0.29 \%$ & $-0.61 \%$ & $0.03 \%$ & $0.63 \%$ & $-0.63 \%$ & 0.56 \\
\hline Heihe & $-3.64 \%$ & $-0.66 \%$ & $-0.12 \%$ & $-0.18 \%$ & $3.72 \%$ & $1.45 \%$ & 1.63 \\
\hline Suihua & $-3.57 \%$ & $2.04 \%$ & $-1.29 \%$ & $0.62 \%$ & $-0.10 \%$ & $3.19 \%$ & 1.80 \\
\hline Daxing'anling & $-0.39 \%$ & $0.58 \%$ & $0.49 \%$ & $-0.52 \%$ & $-1.35 \%$ & $2.29 \%$ & 0.94 \\
\hline
\end{tabular}

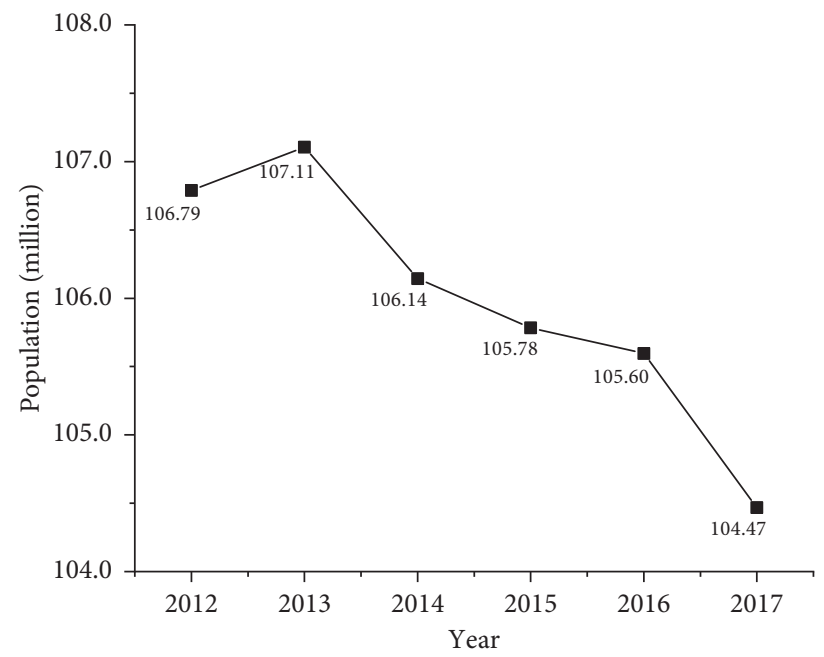

FIgURE 3: Overall estimated population in Northeast China from 2012-2017. 


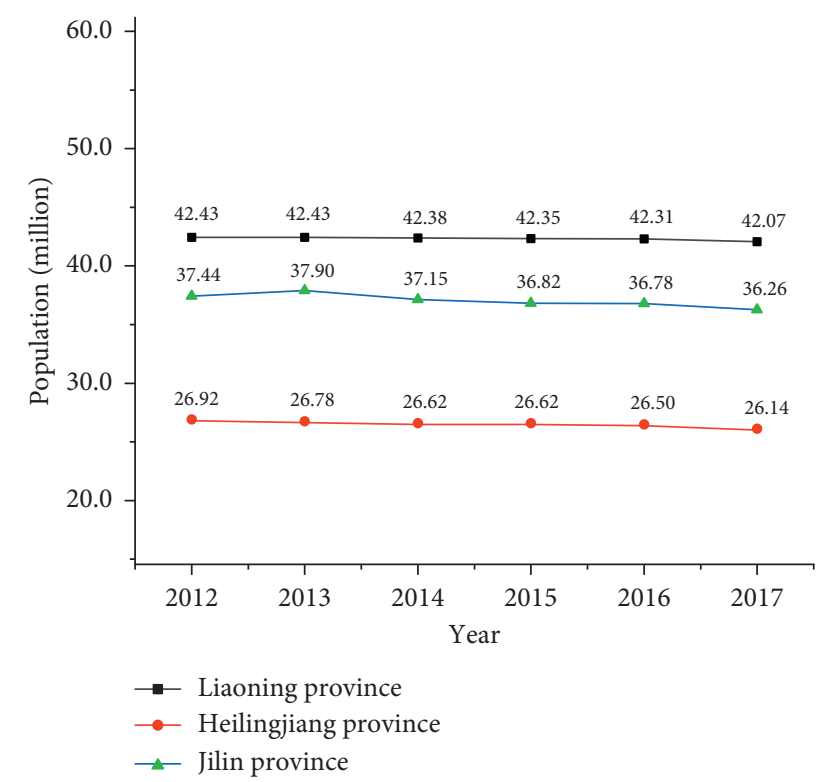

FIgURE 4: Estimated population of Liaoning, Heilongjiang, and Jilin from 2012-2017.

whereas the total population declined in all other years. The population of Northeast China had its largest decrease in 2017.

The population size can, to a certain extent, indirectly reflect economic and social development. Based on Figure 4, the economic development in Northeast China was characterized by a trend of Liaoning $>$ Heilongjiang $>$ Jilin. Compared with Heilongjiang and Jilin, Liaoning is the economic pillar of Northeast China. Based on statistical data, the total GDP of Northeast China in the first three quarters of 2019 was 3.94 trillion yuan, of which Liaoning province accounted for nearly half (48.40\%). Although the economic growth of Liaoning province was lower than the national average, it was significantly higher than that of Heilongiiang and Jilin (https://www.sohu.com/a/366165279_796350).

3.4. Regional Population Comparisons. In terms of population size, from 2012-2017, only Shenyang, Dalian, and Panjin were characterized by an upward trend, with all other cities exhibiting a decline in population (Figure 5(a)). There are four urban agglomerations in Northeast China, i.e., the Harbin-Daqing-Qiqihar Industrial Corridor (centered on Harbin), the Changjitu Pilot Zone (centered on Changchun and Jilin), the Liaoning Coastal Economic Belt (centered on Dalian), and the Shenyang Economic Zone [46, 49]. These four major urban agglomerations have consistently acted as population agglomeration areas, with their respective annual populations far exceeding 4 million people (Figure 5(b)).

As the capital city of Liaoning province, Shenyang is at the center of a regional development strategy known as the Shenyang Economic Development Zone. Shenyang and surrounding cities form a closely connected "regional economic community", which aims to comprehensively revitalize the old industrial base of Liaoning [50,51]. In addition, compared with other provincial capitals, Shenyang's housing prices are more affordable and stable, which attracts a certain amount of migration. Several pending policies and the expansion of college and university enrollment also contribute to the overall increasing population trend of Shenyang [52].

Dalian is known as the "Pearl of the North" and the "Capital of Romance", with a warm temperate continental monsoon climate and marine characteristics. Dalian is the warmest city in Northeast China, and it is characterized by four distinct seasons and offers excellent living conditions for its residents [53]. Moreover, Dalian is surrounded by the sea on three sides. The main industries of Dalian are agriculture, forestry, animal husbandry and fisheries, service industry, and foreign trade. These geographic and climatic conditions attract numerous people to Dalian, such that its overall population has an increasing trend [54, 55].

Panjin City has the densest road and highway network in Liaoning. Panjin's development significantly accelerated after the discovery of its oil fields. The flourishing petrochemical industry of Panjin includes China's largest heavy oil and superheavy oil base, as well as the headquarters of the Liaohe Oilfield. Panjin has a warm temperate continental semihumid monsoon climate with four distinct seasons and a generally pleasant climate. Panjin's developing economy is dominated by agriculture and heavy industry. Its population has an overall increasing trend $[55,56]$.

Figure 6 shows the estimated populations of various cities in Northeast China.

\section{Discussion}

4.1. Population Movement Patterns. The results of this study show that the size and level of economic and social development in a city affect its urban population trends. These findings are consistent with the results of previous studies $[46,48,57]$. The size and distribution of population are closely related to the rate of regional economic and social development, as shown by a number of previous studies that have investigated the different aspects of population distribution [10, 58-60]. Many human activities are highly random in nature [14], which can significantly impact population studies. For example, population shifts become unusually high during holidays, such that we must exclude these months from investigations into the number of permanent urban residents.

In this study, we used NPP-VIIRS NTL data to estimate the population of the three provinces in Northeast China. Holiday months with unusually high population shifts were excluded from the study to avoid affecting the accuracy of the estimation results. The average composite images in March and September, with relatively stable populations, were selected to estimate the annual population of Northeast China. To render the estimation results more comparable, as Northeast China includes different climatic and topographic regions, different cities were selected as the basic population estimation units.

4.2. Limitations. In this study, we estimated the population of 36 cities in Northeast China by performing a third-order 


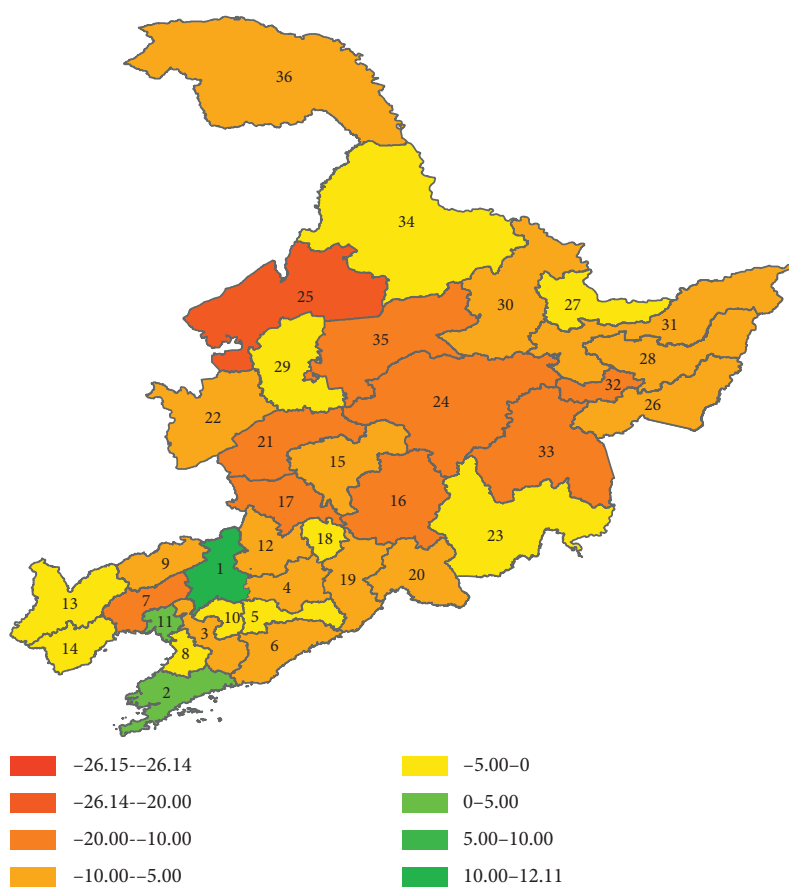

(a)

$\begin{array}{lll}1 \text { Shenyang } & 10 \text { Liaoyang } & 19 \text { Tonghua } \\ 2 \text { Dalian } & 11 \text { Panjin } & 20 \text { Baishan } \\ 3 \text { Anshan } & 12 \text { Tieling } & 21 \text { Songyuan } \\ 4 \text { Fushun } & 13 \text { Chaoyang } & 22 \text { Baicheng } \\ 5 \text { Benxi } & 14 \text { Huludao } & 23 \text { Yanbian (Korean Autonomous Prefecture) } \\ 6 \text { Dandong } & 15 \text { Changchun } & 24 \text { Harbin } \\ 7 \text { Jinzhou } & 16 \text { Jilin } & 25 \text { Qiqihar } \\ 8 \text { Yingkou } & 17 \text { Siping } & 26 \text { Jixi } \\ 9 \text { Fuxin } & 18 \text { Liaoyuan } & 27 \text { Hegang }\end{array}$

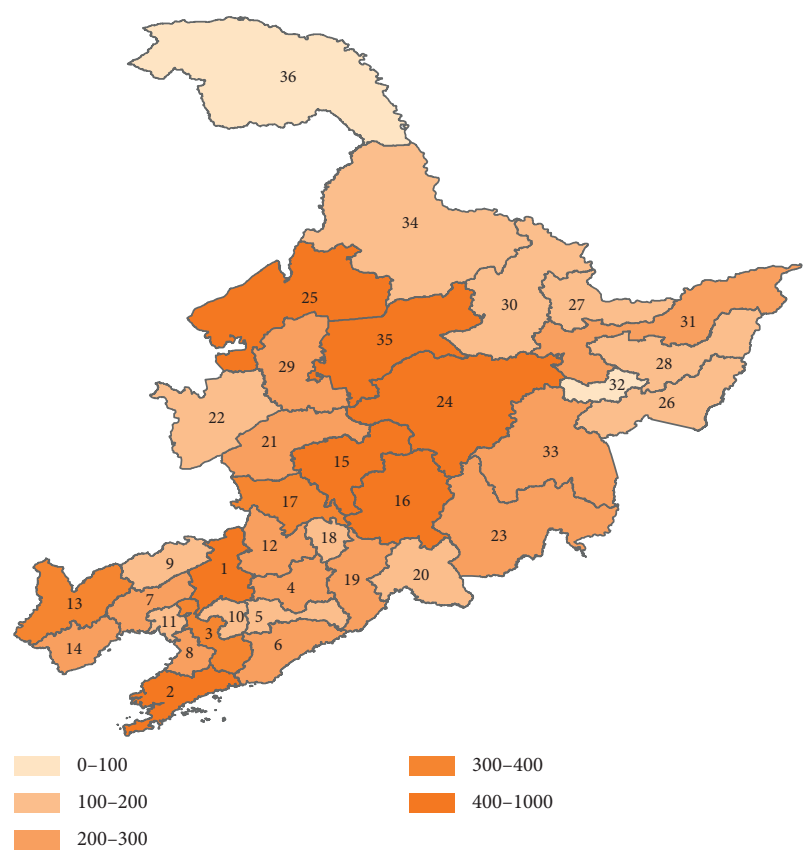

28 Shuangyashan
29 Daqing
30 Yichun
31 Jiamusi
32 Qitaihe
33 Mudanjiang
34 Heihe
35 Suihua
36 Grester Khingan Range

FIGURE 5: (a) Estimation of population differences, 2012-2017. (b) Estimated population distribution in Northeast China, 2017.

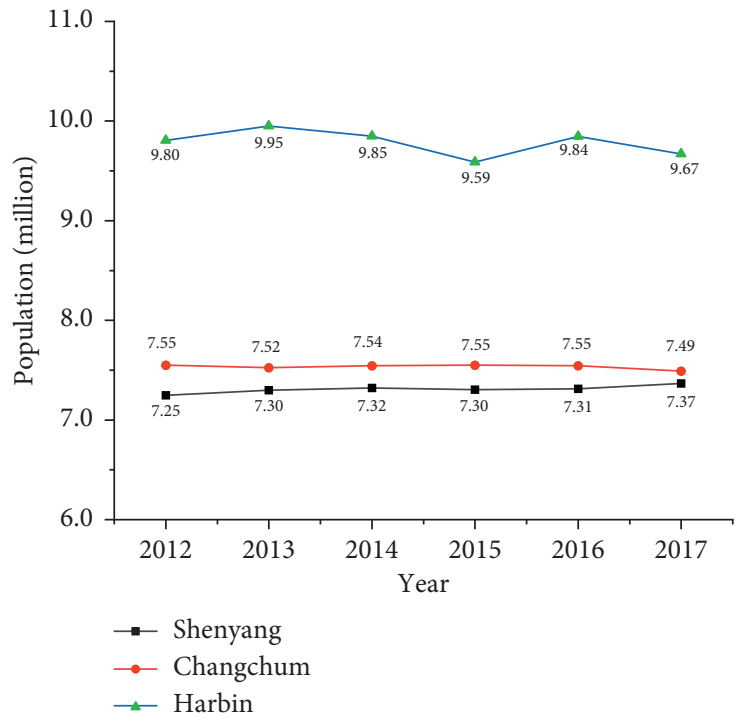

(a)

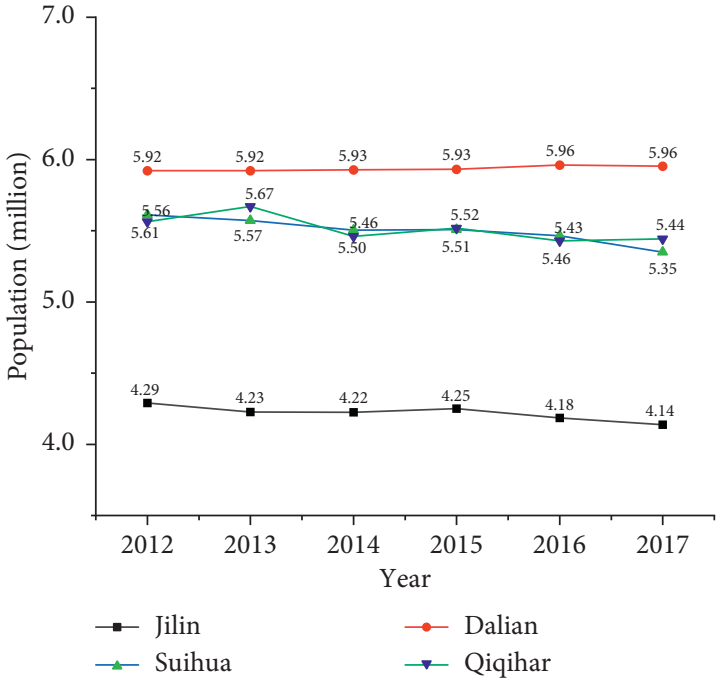

(b)

Figure 6: Continued. 


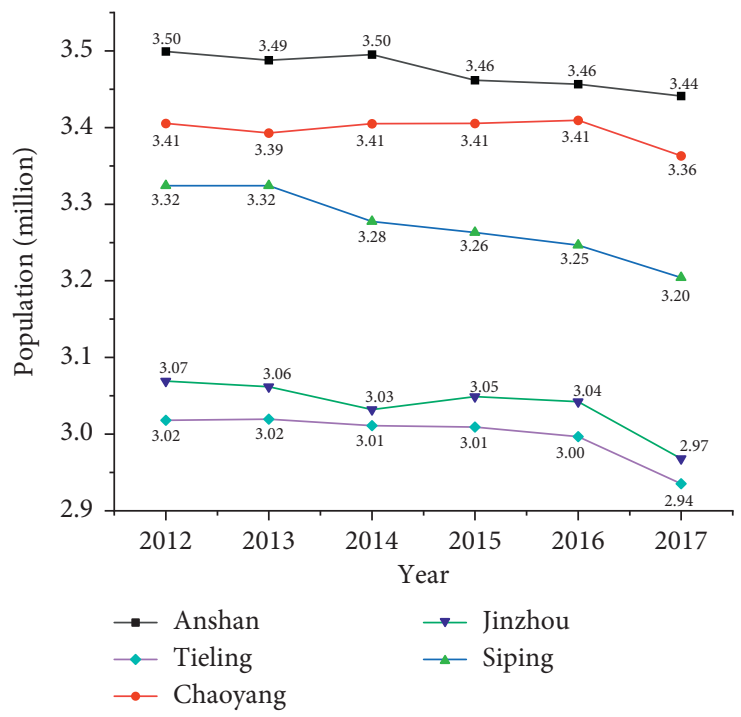

(c)

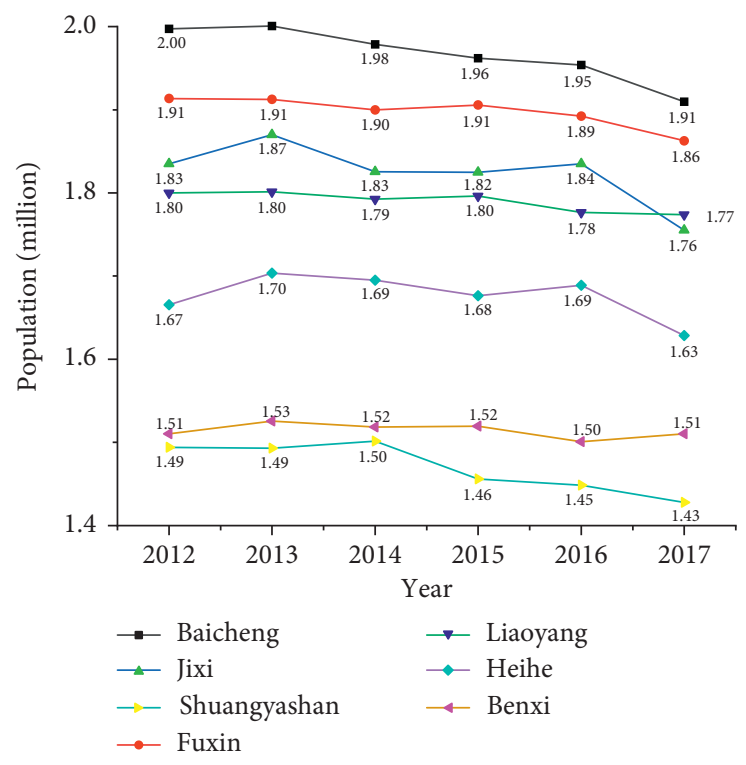

(e)

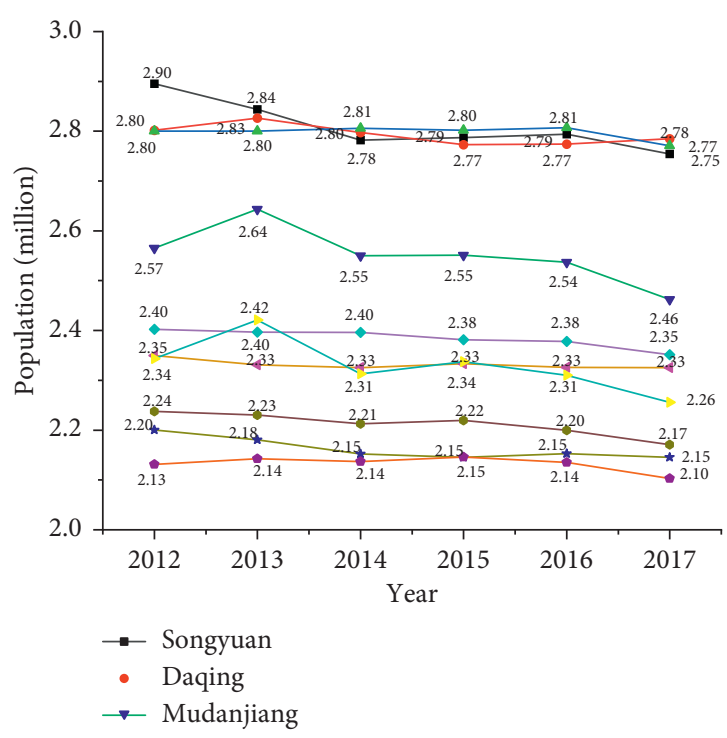

(d)

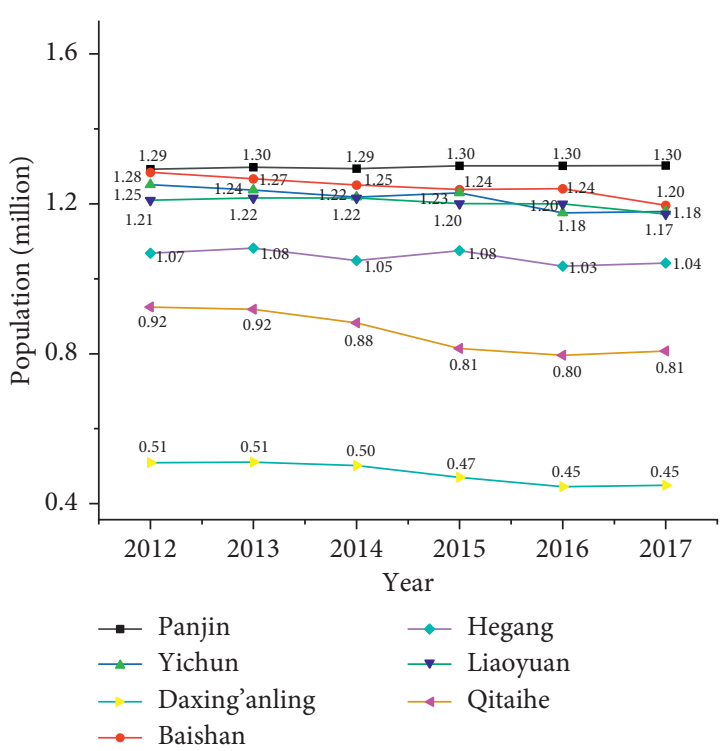

(f)

Figure 6: Estimated population of 36 cities in Northeast China from 2012-2017.

polynomial fitting on annual census data and NTL DN values. Traditional methods to determine the number of permanent urban residents require time-consuming and labor-intensive data collection, which makes it difficult to obtain accurate large-scale statistical data. In contrast, this study provides a more rapid and accurate method to estimate urban populations based on NTL data.

Numerous studies have demonstrated that NPP-VIIRS image data are highly suitable for population spatialization research at both the national and regional scales. These image data, however, do have certain limitations. First, the optimal DN threshold value for lighting in residential areas is still uncertain, which indicates that we cannot effectively exclude image noise and light interference from nonresidential areas, such as factories and bodies of water. Second, the NPP satellite began to collect NTL data in April 2012, which indicates that the time series data used in this study cover a relatively short period and cannot effectively reflect long-term population trends. Finally, as we estimated the urban population via polynomial fitting of the 2012-2017 census and NTL data in this study, the accuracy of the statistical data itself controlled the accuracy of the estimation results. Therefore, the average error should be controlled within $1 \%$ as much as possible.

Despite these limitations, the NPP-VIIRS data are an effective tool for exploring the spatial distribution and spatiotemporal evolution of urban populations, which is of practical significance for the assessment and governance of urban development in China. 


\section{Conclusions}

In this study, a polynomial fitting method was used to estimate the population of 36 cities in Northeast China based on the DN values of NPP-VIIRS NTL imagery. We then determined the spatial and temporal trends in the urban population in this region. Our conclusions are as follows:

(1) From 2012 to 2017, the total population of Northeast China showed a decreasing trend, with each year's population changing by $+316,000,-960,800$, $-359,800,-188,000$, and $-1,127,600$ people, respectively. These results show that population decline is a serious problem in Northeast China.

(2) With the overall declining trend in population in Northeast China, the population growth of Shenyang, Dalian, and Panjin indicates that these cities have relatively good economic development potential and are suitable areas for habitation.

(3) The four major urban agglomerations in Northeast China (the Harbin-Daqing-Qiqihar Industrial Corridor, Changjitu Pilot Zone, Liaoning Coastal Economic Belt, and Shenyang Economic Zone) have consistently acted as population agglomeration areas, with their respective annual populations far exceeding 4 million people.

\section{Data Availability}

The data used to support the findings of this study are available from the corresponding author upon request.

\section{Conflicts of Interest}

The authors declare that they have no conflicts of interest.

\section{Acknowledgments}

This research was supported by the National Natural Science Foundation of China (nos. 41801340 and 41630749), the Natural Science Foundation of Liaoning, China (no. 20180550238), and the Key Research Program of Frontier Sciences by Chinese Academy of Sciences (no. QYZDBSSW-DQC005).

\section{References}

[1] Q Wei, L. Shenghe and J. Fengjun, Calculation and spatial evolution of population loss in Northeast China," Scientia Geographica Sinica, vol. 37, no. 12, pp. 1795-1804, 2017.

[2] K. Yang, S. Zhang, Y. Luo, Q. Xu, and L. Qu, "The widening urbanization gap between the three Northeast Provinces and the Yangtze river delta under China's economic reform from 1984 to 2014," International Journal of Sustainable Development \& World Ecology, vol. 25, no. 3, pp. 262-275, 2018.

[3] E. K. F. Chan, A. Timmermann, B. F. Baldi et al., "Human origins in a southern African palaeo-wetland and first migrations," Nature, vol. 575, no. 7781, pp. 185-189, 2019.

[4] Q. Fu, C. Posth, M. Hajdinjak et al., "The genetic history of ice age Europe,” Nature, vol. 534, no. 7606, pp. 200-205, 2016.
[5] J. Yang, S. Jin, X. Xiao et al., "Local climate zone ventilation and urban land surface temperatures: towards a performancebased and wind-sensitive planning proposal in megacities," Sustainable Cities and Society, vol. 47, Article ID 101487, 2019.

[6] J. Yang, J. Sun, Q. Ge, and X. Li, “Assessing the impacts of urbanization-associated green space on urban land surface temperature: a case study of Dalian, China," Urban Forestry \& Urban Greening, vol. 22, pp. 1-10, 2017.

[7] J. Yang, Y. Wang, and X. Xiao, "Spatial differentiation of urban wind and thermal environment in different grid sizes," Urban Climate, vol. 28, 2019.

[8] A. Guo, J. Yang, X. Xiao, J. Xia, C. Jin, and X. Li, "Influences of urban spatial form on urban heat island effects at the community level in China," Sustainable Cities and Society, vol. 53, Article ID 101972, 2020.

[9] R. H. Adams and J. Page, "Do international migration and remittances reduce poverty in developing countries?" World Development, vol. 33, no. 10, pp. 1645-1669, 2005.

[10] S. Fukuda-Parr, "From the Millennium development goals to the sustainable development goals: shifts in purpose, concept, and politics of global goal setting for development," Gender \& Development, vol. 24, no. 1, pp. 43-52, 2016.

[11] M. Tan, X. Li, S. Li et al., "Modeling population density based on nighttime light images and land use data in China," Applied Geography, vol. 90, pp. 239-247, 2018.

[12] J. F. Wilson, D. Baker, and J. Cheney, "A role for artificial night-time lighting in long-term changes in populations of 100 widespread macro-moths in UK and Ireland: a citizenscience study," Journal of Insect Conservation, vol. 22, no. 1, pp. 1-8, 2018.

[13] B. R. Tripathy, V. Tiwari, V. Pandey et al., "Estimation of urban population dynamics using DMSP-OLS night-time lights time series sensors data," IEEE Sensors Journal, vol. 17, no. 4, pp. 1013-1020, 2017.

[14] D. Stathakis and P. Baltas, "Seasonal population estimates based on night-time lights," Computers, Environment and Urban Systems, vol. 68, pp. 133-141, 2018.

[15] W. Fahui, L. Cuiling, and X. U. Yaping, "Analyzing population density disparity in China with GIS-automated regionalization: the hu line revisited," Chinese Geographical Science, vol. 29, no. 4, pp. 541-552, 2019.

[16] L. He, K. Lo, and Z. Pingyu, "Population shrinkage in resource-dependent cities in China: processes, patterns and drivers," Chinese Geographical Science, vol. 30, no. 1, pp. 1-15, 2020.

[17] X. Yang, T. Ye, N. Zhao et al., "Population mapping with multisensor remote sensing images and point-of-interest data," Remote Sensing, vol. 11, no. 5, p. 574, 2019.

[18] T. Ye, N. Zhao, X. Yang et al., "Improved population mapping for China using remotely sensed and points-of-interest data within a random forests model," Science of the Total Environment, vol. 658, pp. 936-946, 2019.

[19] P. Kumar, H. Sajjad, R. S. Alare, C. D. Elvidge, R. Ahmed, and V. P. Mandal, "Analysis of urban population dynamics based on residential buildings volume in six provinces of Pakistan using operational linescan system sensors," IEEE Sensors Journal, vol. 17, no. 6, pp. 1656-1662, 2017.

[20] R. Wu, D. Yang, J. Dong, L. Zhang, and F. Xia, "Regional inequality in China based on NPP-viirs night-time light imagery," Remote Sensing, vol. 10, no. 2, p. 240, 2018.

[21] K. Shi, C. Huang, and Y. Chen, "Remotely sensed nighttime lights reveal increasing human activities in protected areas of China mainland," Remote Sensing Letters, vol. 9, no. 5, pp. $468-477,2018$. 
[22] J. Zhu, B. Li, and B.-J. He, "Is linked migration overlooked in peri-urban Shanghai? Uncovering the domino effect of driving away interregional migrants," Habitat International, vol. 94, Article ID 102046, 2019.

[23] W. Li, B. Sun, J. Zhao, and T. Zhang, "Economic performance of spatial structure in Chinese prefecture regions: evidence from night-time satellite imagery," Habitat International, vol. 76, pp. 29-39, 2018.

[24] F. Bickenbach, E. Bode, P. Nunnenkamp, and M. Söder, "Night lights and regional GDP," Review of World Economics, vol. 152, no. 2, pp. 425-447, 2016.

[25] M. M. Bennett and L. C. Smith, "Using multitemporal nighttime lights data to compare regional development in Russia and China, 1992-2012," International Journal of Remote Sensing, vol. 38, no. 21, pp. 5962-5991, 2017.

[26] K. Yang, Y. Luo, K. Chen et al., "Spatial-temporal variations in urbanization in Kunming and their impact on urban lake water quality," Land Degradation \& Developmen, 2020.

[27] K. Yang, Z. Yu, Y. Luo, X. Zhou, and C. Shang, "Spatialtemporal variation of lake surface water temperature and its driving factors in Yunnan-Guizhou plateau," Water Resources Research, vol. 55, no. 6, 2019.

[28] Q. Zheng, R. Jiang, K. Wang et al., "Monitoring the trajectory of urban nighttime light hotspots using a Gaussian volume model," International Journal of Applied Earth Observation and Geoinformation, vol. 65, pp. 24-34, 2018.

[29] B.-J. He, Z.-Q. Zhao, L.-D. Shen, H.-B. Wang, and L.-G. Li, "An approach to examining performances of cool/hot sources in mitigating/enhancing land surface temperature under different temperature backgrounds based on landsat 8 image," Sustainable Cities and Society, vol. 44, pp. 416-427, 2019.

[30] L. Jiang, B. Xue, Z. Ma, L. Yu, B. Huang, and X. Chen, "A lifecycle based co-benefits analysis of biomass pellet production in China," Renewable Energy, vol. 154, pp. 445-452, 2020.

[31] C. Cao, J. Xiong, and S. Blonski, "Suomi NPP VIIRS sensor data record verification, validation, and long-term performance monitoring," Journal of Geophysical Research: Atmospheres, vol. 118, no. 20, pp. 611-664, 2013.

[32] N. Levin, "The impact of seasonal changes on observed nighttime brightness from 2014 to 2015 monthly VIIRS DNB composites," Remote Sensing of Environment, vol. 193, pp. 150-164, 2017.

[33] B. Pandey, Q. Zhang, and K. C. Seto, "Comparative evaluation of relative calibration methods for dmsp/ols nighttime lights," Remote Sensing of Environment Remote Sensing of Environment, vol. 195, pp. 67-78, 2017.

[34] S. Song, Y. Bailang, and W. Jianping, "Methods for deriving urban built 2 up area using night 2 light data :assessment and application," Remote Sensing Technology and Application, vol. 26, no. 2, pp. 169-176, 2011.

[35] S. Jiang, J. Li, P. Duan, and Y. Wei, "An image layer difference index method to extract light area from NPP/VIIRS nighttime light monthly data," International Journal of Remote Sensing, vol. 40, no. 12, pp. 4839-4855, 2019.

[36] L. Neri, L. Coscieme, B. F. Giannetti, and F. M. Pulselli, "Imputing missing data in non-renewable empower time series from night-time lights observations," Ecological Indicators Integrating Monitoring Assessment \& Management, vol. 84, pp. 106-118, 2018.

[37] M. M. Bennett and L. C. Smith, "Advances in using multitemporal night-time lights satellite imagery to detect, estimate, and monitor socioeconomic dynamics," Remote Sensing of Environment, vol. 192, pp. 176-197, 2017.
[38] Y. Zhou, T. Ma, C. Zhou, and T. Xu, "Nighttime light derived assessment of regional inequality of socioeconomic development in China," Remote Sensing, vol. 7, no. 2, pp. 12421262, 2015.

[39] T. A. Croft, "Nighttime images of the earth from space," Scientific American, vol. 239, no. 1, pp. 86-98, 1978.

[40] P. Sutton, C. Roberts, and C. Elvidge, "A comparison of nighttime satellite imagery and population density for the continental United States," Photogrammetric Engineering and Remote Sensing, vol. 63, no. 11, pp. 1303-1313, 1997.

[41] W. Kejing, C. Hongyan, and Y. Xiaohuan, "Multiple scale spatialization of demographic data with multi-factor linear regression and geographically weighted regression models," Progress in Geography, vol. 35, no. 12, pp. 1494-1505, 2016.

[42] L. Xiang, C. Zhenjie, and W. Jiexuan, "Gridding methods of city permanent population based on night light data and spatial regression models," Journal of Geo-Information Science, vol. 19, no. 10, pp. 1298-1305, 2017.

[43] K. Shi, B. Yu, Y. Huang et al., "Evaluating the ability of NPPviirs nighttime light data to estimate the gross domestic product and the electric power consumption of China at multiple scales: a comparison with DMSP-OLS data," Remote Sensing, vol. 6, no. 2, pp. 1705-1724, 2014.

[44] C. D. Elvidge, K. E. Baugh, E. A. Kihn, H. W. Kroehl, E. R. Davis, and C. W. Davis, "Relation between satellite observed visible-near infrared emissions, population, economic activity and electric power consumption," International Journal of Remote Sensing, vol. 18, no. 6, pp. 1373-1379, 1997.

[45] D. Leilei, P. Jinghu, and F. Yaya, "Spatial difference pattern of house vacancy in China from nighttime light view," Economic Geography, vol. 37, no. 9, pp. 62-69, 2017.

[46] Y. Tingting, S. Yuxiang, and H. Feilong, "Space pattern evolution of population distribution and the driving factors in Northeast China," Scientia Geographica Sinica, vol. 37, no. 5, pp. 709-717, 2017.

[47] D. Chengrong, L. Lidan, and Z. Xiangjiang, "Major challenges for China's floating population and policy suggestions: an analysis of the 2010 population census data," Population Research, vol. 37, no. 2, pp. 17-24, 2013.

[48] L. Yanling and F. Jian, "Characteristics and impact factors of migration in China: based on the analysis of the Sixth census data," Human Geography, vol. 29, no. 2, pp. 129-137, 2014.

[49] S. J. Wang, S. Yang, and Z. X. Feng, "Pattern and progress of large urban agglomerations and urban flows intensity in Northeast China," Scientia Geographica Sinica, vol. 31, no. 3, pp. 287-294, 2011.

[50] Z.-Q. Zhao, B.-J. He, L.-G. Li, H.-B. Wang, and A. Darko, "Profile and concentric zonal analysis of relationships between land use/land cover and land surface temperature: case study of Shenyang, China," Energy and Buildings, vol. 155, pp. 282-295, 2017.

[51] B. Xue, L. Zhang, Y. Geng, B. Mitchell, and W. Ren, "Extended land-use coding system and its application in urban brownfield redevelopment: case study of tiexi district in Shenyang, China," Journal of Urban Planning \& Development, vol. 142, no. 3, Article ID 5015014, 2016.

[52] P. Zhang, S. Fei, and L. He, "Coordination degree of urban population, economy, space, and environment in Shenyang since 1990," China Population Resources \& Environment, vol. 18, no. 2, p. 119, 2008.

[53] L. I. Xue-Ming and W. W. Liu, "An esfimation on the sense of belonging of city housing plot environment:taking dalian as 
an example," Geographical Research, vol. 25, no. 5, pp. 785791, 2006.

[54] L. I. He, P. Y. Zhang, and W. X. Liu, "Assessment of coordination degree between environment and economy of liaoning province in China during 1990-2003," Scientia Geographica Sinica, vol. 27, no. 4, pp. 486-492, 2007.

[55] G. Mei, L. Dong, C. Tian, and K. E.. Lina, "The research for liaoning environmental efficiency and spatial-temporal differentiation," Geographical Research, 2014.

[56] H. J. Li, Q. B. Wang, F. J. Sun, and C. L. Sun, "Study on land use/land cover changes and driving forces in Panjin city," Research of Agricultural Modernization, vol. 30, no. 2, pp. 212-215, 2009.

[57] P. Sun, S. Ding, and C. Xiu, "Population-economy-Space urbanization of Northeast China," Scientia Geographica Sinica, vol. 32, no. 4, pp. 450-457, 2012.

[58] X. Li, S. Huang, J. Chen, and Q. Chen, "Analysis of the driving factors of U.S. domestic population mobility," Physica a: Statistical Mechanics and Its Applications, vol. 539, p. 122984, 2020.

[59] F. Simini, M. C. González, A. Maritan, and A.-L. Barabási, “A universal model for mobility and migration patterns," Nature, vol. 484, no. 7392, pp. 96-100, 2012.

[60] I. Mathieson, S. Alpaslan-Roodenberg, and C. Posth, "The genomic history of Southeastern Europe," Nature, vol. 555, no. 7695, pp. 197-203, 2018. 